\title{
Integrating Project-Based Learning in Teaching English as a Foreign Language
}

\author{
Katekina A.A. \\ University of management "TISBI" \\ Kazan, Russia \\ akatekina@gmail.com
}

\author{
Zaynullina G.I. \\ University of management "TISBI" \\ Kazan, Russia \\ gulshat.kaz@mail.ru
}

\author{
Basenko I.V. \\ University of management "TISBI" \\ Kazan, Russia \\ inessa_29@mail.ru
}

\begin{abstract}
The purpose of this study was to investigate the effectiveness of project-based learning (PBL) in the formation of intercultural foreign language competence of future specialists in social and cultural services and tourism. The author has proved PBL to be effective in helping students acquire a wide range of skills while encouraging use of their creativity and critical thinking and problem-solving skills.
\end{abstract}

Keywords-intercultural foreign language competence; project-based method; socio-cultural service and tourism; cultural paradigm.

\section{INTRODUCTION}

At the present stage of vocational education development, characterized by dynamism and variability, the project type of culture begins to dominate in the mind of a professional, which gradually becomes one of the central mechanisms of its transformative activity. Vocational training is understood as training based on the needs of students in learning a foreign language, dictated by the characteristics of the future profession or specialty [6]. Foreign language, especially English, is irreplaceable in the sphere of business communication $[12,916]$.

The formation of the design culture of a professional specialist becomes the basis of a new educational paradigm of the 21st century. The greatest value is acquired by the knowledge obtained by students - subjects of educational and professional activity on the basis of independence and creativity.

The structure and content of a future specialist education in the field of service and tourism today do not correspond to the structures of modern culture and professional activity. Of the three forms of "spiritual objectivity" - knowledge, value and project in the space of education, one is duly reflected - knowledge. If values are somehow presented in an edifying sense, then projectivity is absent altogether [3].
Both knowledge, and values, and the project (spiritual objectivity) are present in the process of preparing a student for future professional activities in the field of service and tourism in such forms that can ensure harmonization of his or her environment. In this context, we define the personality of a future specialist in socio-cultural services and tourism as an intensely growing humanitarian system involving the design of an educational space that develops in harmony with social culture.

The data obtained as a result of the work programs analysis, visits and discussions of a foreign language teachers classes, individual and group conversations with them during extracurricular time, convince that the formation of a foreign language communicative competence is the most difficult and vulnerable place in the educational process of a foreign language.

The forming paradigm of higher education is defined as "innovative-projective". In this context, projectivity is understood as the ontological quality of culture, updated by the modern dynamic post-industrial phase of civilized development. Effective technologies for the formation of intercultural foreign language competence of students of professional educational institutions of the socio-cultural service profile and tourism in the context of the educational cultural paradigm have identified design technologies. The project-based method is a pedagogical technology, focused not on the integration of factual knowledge, but on their application and the acquisition of new ones. The integration of students in project's creation gives them the opportunity to learn new ways of human activity in the socio-cultural environment. Appropriate and methodologically justified is, therefore, professionally-communicative training in a foreign language, involving the training of students in professionally-oriented foreign language communication [8, 152]. For English as a second language students, PBL typically integrates four skills of listening, speaking, reading 
and writing, encouraging the use of English outside the classroom [9]. PBL is a dynamic approach to teaching in which students explore real-world problems and challenges, simultaneously developing cross-curriculum skills while working in small collaborative groups or individually [1]. PBL is considered as student-centred since students are driven by the need to create an end-product which brings them opportunities to develop their confidence and independence in learning English as a foreign language [2]. Another advantage of PBL in an English language classroom lies in the transfer of responsibility for the management of learning from teacher to learners [10]. Learning through PBL becomes fruitful for learners because they exhibit their abilities to plan, manage, and accomplish projects through their content knowledge and language skills [4].

\section{RESEARCH METHODOLOGY}

Our experimental study took place at the University of Management TISBI. Eighty-three students of the Service Management Department were involved in the experiment.

As a control point, students carried out projects that integrate the rational and emotional capabilities of the individual in the context of intercultural foreign language communication. It contributes to a significant reduction in the psychological language barrier. The most interesting were the projects devoted to the modern world of Englishspeaking countries, and the project related to fiction. Thus, students, in addition to the formation of foreign language competence, studied the deep layer of English-language culture.

As components of the formed competence, we highlighted the emotional-value, cognitive, communicative, and operational-activity components.

During the development of methods for assessing the components of the competence written above, the authors checked it for substantive and criteria validity, for which a set of personality properties and types of activities for a particular component were determined. The current validity of the test was verified by examining the correlation of test results with independent criteria.

The peer review method was also applied in order to ensure the validity of the tests. Teachers assessed the level of component formation informing students about this. For each test item, we found the average.

We conducted an analysis of the results, referring to $\mathrm{O}$. V. Nikiforov's gradation.

Having studied the methods of diagnosing personality and achievements, we adopted the following gradation for the levels of formation of competency components: less than 0.45 from the maximum (i.e., less than 22 points) - low level; from 0.46 to 0.74 - average level; more than 0.75 from the maximum (more than 37 points) - a high level.

To identify the level of formation of each of the four components of the studied competence, we used the author's test questionnaires. Students should evaluate the given knowledge by significance for them on a 5-point scale: ("yes" - 5 points, "rather yes" - 4 points, "rather no" - 3 points, "no" - 2 points, "definitely not "- 1 point).

\section{RESULTS}

At the end of the $3 \mathrm{~d}$ year, we re-diagnosed the formation of the components of multicultural foreign language competence among students, the results of which were considered necessary to present in the form of a histogram showing the diagnostic data before and after the experiment (Fig. 1).

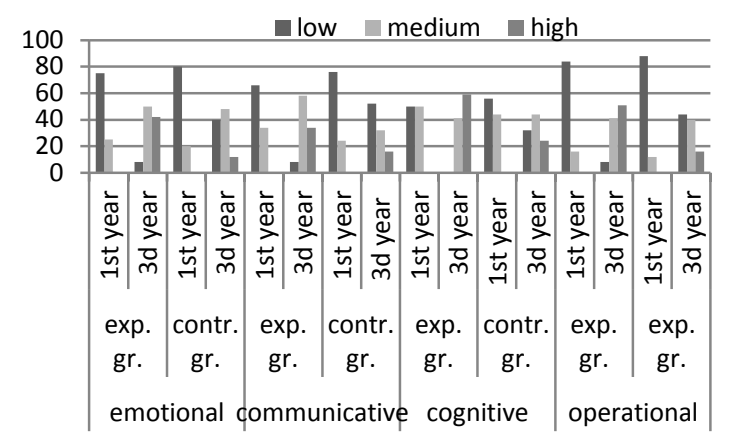

Fig. 1. The dynamics of the intercultural foreign language competence of $1^{\text {st }}$ year and $3^{\text {rd }}$ year students of Hospitality Management

The histogram displays that, the result of an experimental study is an increase in the level of intercultural foreign language competence components formation among students of experimental groups. This fact indicates that we correctly took into account the psychological and pedagogical conditions for the formation of multicultural foreign language competence.

The formation of students intercultural foreign language competence was carried out on the basis of humanization ideas implementation, when the purpose and meaning of the educational process is the development and selfdevelopment of individualization, self-actualization of a future specialist personality. A student studies culture through language, through texts, authentic audio and video materials, but to study culture, it is absolutely not enough to simply explain any regional geographic reality [11, 981]. A promising direction in foreign language training is projects that implement the integration of rational and emotional capabilities of a person in the context of intercultural foreign language communication, which contributes to a significant reduction in the psychological language barrier [7, 76].

An experimental verification of the conditions for the formation of multicultural foreign language competence of a future specialist in socio-cultural services and tourism and the results obtained in the course of diagnostics confirmed the productivity of their use as an innovative means of assessing the effectiveness of the process under study.

\section{CONCLUSION}

The results of the experiment also showed that there are no ready-made algorithms, the use of which immediately solves all problems of forming a multicultural foreign language competence of a future specialist in socio-cultural service and tourism. We can ascertain the possibility and 
efficiency of using the developed and tested conditions for the formation of multicultural foreign language competence of a future specialist in the process of studying other educational disciplines that have their own specifics, which involves the creative development of our research results. In the future, the presented work could become the basis for further research on the possibilities of forming a multicultural foreign language competence of a future specialist of other professional profiles.

\section{References}

[1] Edutopia. Tech Forum. 2013. URL: http://techlearning.com/default.aspx?tabid=67\&entryid=509.

[2] Fried-Booth D. L., Project work. Oxford: Oxford University Press. 2012, pp. 6.

[3] Kagan, M.S. Philosophy of culture. St. Petersburg. 1996, pp.295-296.

[4] Kloppenborg, T. J., Baucus M. S. Project management in local nonprofit organisations: Engaging students in problem-based learning. Journal of Management Education. 2004, vol. 28, pp. 610-630.

[5] Lezhnina L.V., Morova N.S., Domracheva S.A. Multicultural Education: From Idea to Project. SOCIOINT 2017: 4th International Conference on Education, Social Sciences and Humanities. Abstracts \& Proceedings. (Dubai, 10-12 July 2017). TURKEY, Istanbul: OCERINT. 2017, pp. 813-816.

[6] Obraztsov, P.I, Ivanova O.Yu. Professionally-oriented teaching of a foreign language at non-linguistic faculties of universities. Orel: OSU. 2005. pp.20-23, 92-97.

[7] Petuhova, A. A. Method of projects in foreign language lessons. Scientific and methodical electronic journal "Concept". 2017, vol. 33, pp. 75-80.

[8] Pokushalova, L. V. Formation of foreign language professionally oriented competence among students of a technical university. Young scientist. 2011, vol. 2, 3, pp. 151-154.

[9] Simonova, K.N. Project-based English language teaching. Modern interactive learning system in the context of modernization of higher education. Materials of the scientific-methodical conference: South Federal University. Rostov-on-Don: Southern Federal University Press. 2015, pp. 236-240

[10] Tudor I., Learner-centredness as Language Education. Cambridge: Cambridge University Press. 1996, pp. 219.

[11] Tukaeva, R.N., Solodkova I.S., Nurutdinova A.R., Katekina A.A. Intercultural communicative competence in hospitality managers' training and regional tourism attractiveness. Educational Researcher. 2018, vol. 47, 9(2), pp. 979-985.

[12] Tukaeva, R.N., Katekina A.A. Intercultural communicative competence in polyethnic society. American Journal of Philology, 2018, vol. 139, 4(2), pp. 912-917. 